\title{
PEMODELAN SISTEM TERDISTRIBUSI MENGGUNAKAN METODE HIRARKI PADA POWER PLANT PEMBANGKIT LISTRIK TENAGA UAP (PLTU)
}

\author{
${ }^{1}$ Ilmi Rizki Imaduddin $\&^{2}$ Hendi Purnata \\ ${ }^{12}$ Institut Teknologi Sepuluh Nopember \\ Email: hendipurnata@gmail.com
}

\begin{abstract}
Abstrak
Sistem kendali berhirarki biasanya untuk mengatasi suatu sistem pengendalian yang kompleks. Prinsip sistem kendali kompleks tidak bisa diterapkan langsung secara efektif dan efisien hal ini disebebakan oleh sistemnya terlalu besar dan permasalahan terlalu kompleks. Sistem kendali berhirarki mempunyai input dan output berjumlah besar. Pada sistem kendali berhirarki, komponennya melakukan berbagai macam interaksi dinamis dan sistem ini mendapatkan bermacam-macam gangguan. Model matematis dari sistem ini mempunyai orde dinamik yang besar dan mencakup banyak parameter sistem. Pencarian alternative dalam kendali suatu sistem berdimensi besar akan menyebabkan pembagian keseluruhan dalam subsub permasalahan. Hasil dari penelitian ini sistem mempunyai input langsung menjadi output (troughput) syarat input dan outputnya reachable sehingga sistem bisa dikatakan controllable dan observable. Untuk menghasilkan sistem stabil di ketahui bahwa persamaan karakteristik dari sistem tersebut berada di sebelah kiri bidang S. Pada penelitian ini terdapat satu eigen value yang berada di sebelah kanan bidang $S$ maka distabilkan menggunakan pengendalian terdesentralisasi dengan memberikan kompensator
\end{abstract}

Keyword: sistem kompleks, hirarki, desentralisasi, PLTU

\section{Pendahuluan}

Teknologi yang telah berkembang pesat, dalam sistem kontrol ada beberpa hal yang tidak bisa mengatasi prinsip efisiensi dan efektifitas. Sistem Multiple Input Multiple Output (MIMO) pada sistem kendali bertujuan agar suatu sistem bekerja bersamaan untuk mencapai efisiensi dan efektifitas, akan tetapi dalam sistem (MIMO) kurang bisa diaplikasikan.

Sistem kendali skala besar pertama kali dikenalkan pada tahun 1960 oleh Dantzing dan Wolfe yang mendekomposisikan permasalahan pemrograman linear. Kemudian dikembangkan dengan pendekatan multilevel oleh Mesarovic tahun 1970 dan Cohen tahun 1978. Sistem skala besar mempunyai sejumlah input dan output dengan komponennya melakukan berbagai interaksi dinamis. Sistem ini melalui sistem lingkungannya mempunyai orde dinamik yang besar dan mencakup banyak parameter sistem.
Ide tentang sistem skala besar datang pada saat permasalahan kendali yang pada praktiknya tidak dapat diterapkan secara efisien oleh prinsip dan metode sistem multivariable. Beberapa ilustrasi seperti pada sistem tenaga multiarea dengan beberapa unit pembangkit tenaga yang mendistribusikan daya listrik ke banyak tempat, sistem coupled water reservoir yang sarat dengan kompleksitas interaksi dinamis antar reservoir, proses pembuatan semen dan power plant.

Kesulitan untuk mengendalikan suatu sistem berdimensi besar menyebabkan lebih menguntungkan untuk membagi kesuluruhan permasalahan ke dalam sub-sub permasalahan yang lebih kecil untuk kemudian dipecahkan secara terpisah dan digabungkan kembali solusi-solusinya untuk mendapatkan suatu solusi global. Sub-sub permasalahan tersebut tidak sepenuhnya independen. Beberapa koordinasi atau modifikasi solusi dari sub-sub permasalahan tersebut dibutuhkan untuk mengatur hubungan antar setiap sub permasalahan. Upaya ini dibutuhkan untuk menyesuaikan sub-sub permasalahan tersebut dalam suatu sistem komputasi terdistribusi. Karena itu dibutuhkan konsep dan teknik untuk memformulasikan suatu permasalahan dan memecahkan sub permasalahan tersebut sebagai suatu sistem pengendalian terdistribusi (Distributed Control System/DCS).

\section{Diskusi}

\subsection{Strategi Pengendalian}

Pada sistem dan kontrol terdapat beberapa strategi pengendalian dalam hirarki agar suatu sistem tersebut dapat didekompoisiskan yaitu sistem yang besar menjadi beberapa sub sistem yang relative kecil yang terinterkoneksi satu sama lain.

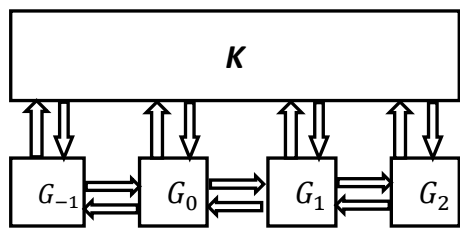

Gambar 1 Sistem Centralisasi 
Sistem sentralisasi merupakan sistem dimana suatu element-elementnya berpusat. kelebihan sistem ini adalah dimana gain $\mathrm{K}$ atau pusat sentralisasi untuk mengambil suatu keputusan tidak berpengaruh kepada siapa pun.

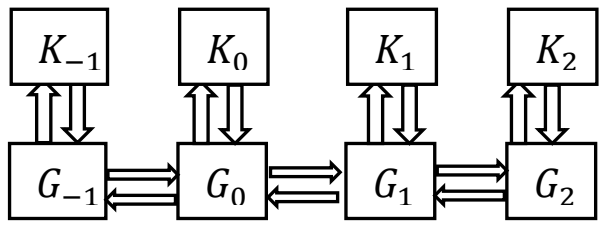

\section{Gambar 2 Sistem Desentralisasi}

sistem desentralisasi merupakan suatu sistem yang mempunyai gain $\mathrm{K}$ sendiri untuk mengatur suatu sub sistem sendiri.

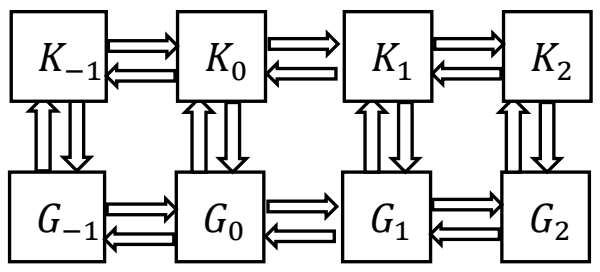

Gambar 3 Sistem Distribus

Sistem distriubusi dimana sistem satu dan sistem lain dalam satu jaringan dan saling berkomunikasi.

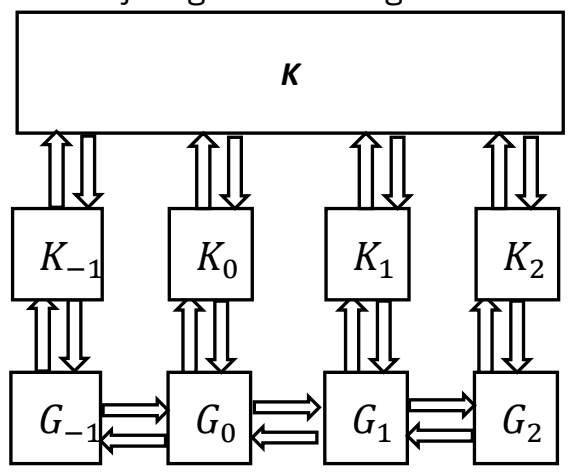

Gambar 4 Sistem Multilevel

Sistem multilevel adalah gabungan antara sistem sentralisasi dan disentralisasi dimana terdapat gain $\mathrm{K}$ yang dapat mengatur element-element dibawahnya.
Pada power plant PLTU startegi pengendalian menggunakan sistem multilevel dimana dari suatu proses ke proses lain saling berhubungan dan dapat di monitoring agar bisa memperoleh suatu proses yang diinginkan.

\subsection{Model Interaksi}

Model interaksi pada sistem pengendalian berhirarki dapat dimodelkan dalam bentuk model seperti pada gambar 5 . Dengan $u_{1}=$ eksternal input ke subsistem 1, $y_{1}=$ ekesternal output dari susbsistem $1, s_{1}=$ internal input ke subsistem 1 yang menyatakan pengaruh dari subsistem yang lain, $z_{1}=$ internal output dari subsistem 1 yang mempengaruhi subsistem yang lain dan $x_{1}=$ state subsistem 1.

Persamaan model interaksi

$\dot{x}=A_{i} x_{i}+B_{i} u_{i}+E_{i} s_{i}$

$y_{i}=C_{i} x_{i}+D_{i} u_{i}+F_{i} s_{i}$

$z_{i}=C_{z i} x+D_{z i} u_{i}+F_{z i} s_{i}$

$s=L z$ dimana $i=1,2,3 \ldots N=$ banyakanya subsistem

Bila interaksi antara subsistem lemah ( $(=0)$, maka:

$\dot{x}=A_{i} x_{i}+B_{i} u_{i}$

$y_{i}=C_{i} x_{i}+D_{i} u_{i}$

Berarti sistem diatas menjadi subsistem-subsistem yang independent, dengan

$$
x=\left[\begin{array}{c}
x_{1} \\
x_{2} \\
\vdots \\
x_{N}
\end{array}\right], u=\left[\begin{array}{c}
u_{1} \\
u_{2} \\
\vdots \\
u_{N}
\end{array}\right], s=\left[\begin{array}{c}
s_{1} \\
s_{2} \\
\vdots \\
s_{N}
\end{array}\right], z=\left[\begin{array}{c}
z_{1} \\
z_{2} \\
\vdots \\
z_{N}
\end{array}\right]
$$

Maka,

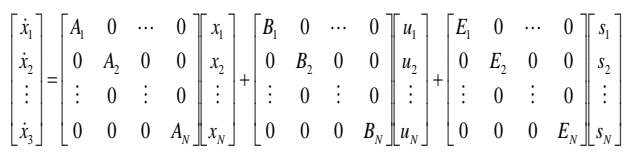

Bila sistem tidak memiiki troughput (input langsung menjdai output), maka persamaan menjadi:

$$
\begin{aligned}
& \dot{x}=A x+B u \\
& y=C x
\end{aligned}
$$

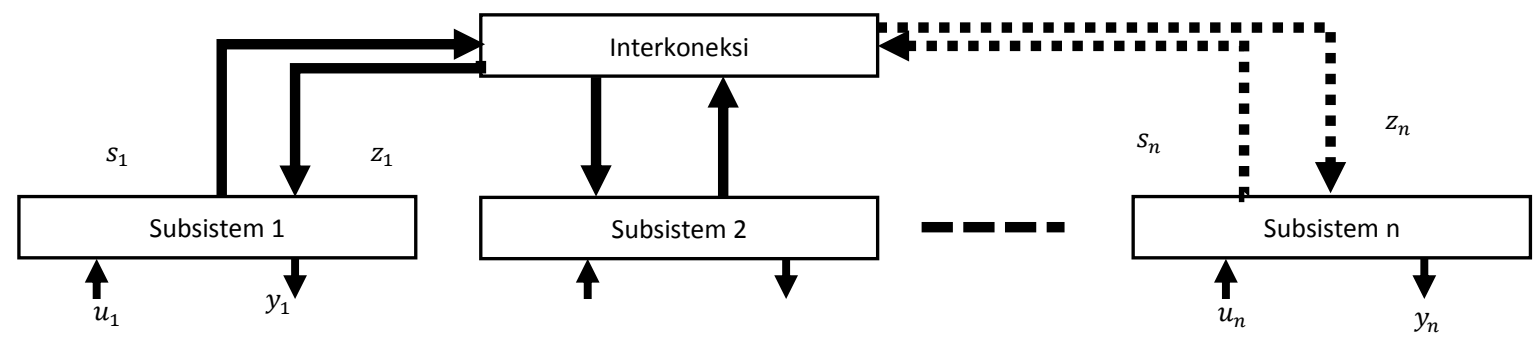

Gambar 5 Model Interaksi 
Dengan $A=\operatorname{diag} A_{i}+\left(\operatorname{diag} E_{i}\right) L \operatorname{diag} C_{z i}$

$B=\operatorname{diag} B_{i}$

$C=\operatorname{diag} C_{i}$

$D=0$

Model diatas sering dinamakan model input output.

\subsection{Dekomposisi Berdasarkan Strongly Coupled Sistem (SCS)}

Pada persamaan (1) sustau sistem dapat didekomposisikan menjadi beberapa subsistemsubsistem dengan menyusunnya secara hirarki. Adapun matriks L tersebut adalah

$L=\left(\begin{array}{cccc}L_{11} & L_{12} & \ldots & L_{1 N} \\ L_{21} & \ldots & \ldots & \vdots \\ \vdots & \vdots & \vdots & \vdots \\ L_{N 1} & \ldots & \ldots & L_{44}\end{array}\right)$

dengan elemen $(L)= \begin{cases}1 & \text { bila } L_{l j}=0 \\ 0 & \text { bila } L_{l j} \neq 0\end{cases}$

Dengan demikian diperoleh beberpa subsistem dengan interaksi yang diberikan oleh (L). Kemudian diadakan pengaturan ulang terhadap kondisi (L) sehingga diperoleh matrik lower diagonal.

$L=\left[\begin{array}{cccc}L_{11} & 0 & \cdots & 0 \\ L_{21} & L_{22} & \cdots & \vdots \\ \vdots & \vdots & L_{33} & \vdots \\ L_{N 1} & L_{N 2} & \cdots & L_{N N}\end{array}\right]$

Pengelompokan tersebut berdasaarkan pada graph struktur dari sistem dengan melihat keadaan matrik L, dengan syarat:
1. Dua Vertex yang strongly coupled berada dalam satu kelas yang ekuivalenya sama

2. Himpunan vertex $\mathrm{N}$ oleh matrik $\mathrm{L}$ didekomposisi menjadi beberapa kelas ekuivalen.

3. Dengan satu transformasi urutan dari vertex dan kelasnya dibuat supaya diperoleh L' yang berupa matrik lower diagonal

4. $L^{\prime}=P^{\prime} L P$

Penelitian ini menggunakan metode hirarki yaitu memodelkan suatu sistem besar dengan menggunakan pengaturan berjenjang kemudian sistem besar didiekomposisi menjadi beberapa sub sistem yang relatif kecil sehingga terinterkoneksi satu sama lain. Metode ini diharapkan dapat merancang sistem yang sesuai untuk tiap subsistem dari keseluruhan sistem yaitu baik secara desentralisasi maupun sentralisasi. Metode ini dilakukan dengan pendekatan dengan fixed mode desentralisasi dimana untuk menstabilkan sistem dapat dilakukan dengan memberikan kompensator terdesentralisasi.

\section{Hasil Penelitian}

Pada sistem kendali pada power plant menggunakan signal processing sebagaimana terlihat pada gambar 6 di bawah.

Pada gambar 6 tampak bahwa informasi sebagai berikut:

$S_{2}$ menginformasikan $z_{1}$

$S_{3}$ menginformasikan $z_{2}$ dan $z_{5}$

$S_{4}$ menginformasikan $z_{3}$

$S_{5}$ menginformasikan $z_{3}$

$s_{6}$ menginformasikan $z_{5}$

$s_{7}$ menginformasikan $z_{6}$

$S_{8}$ menginformasikan $Z_{7}$

Dengan kondisi fisik dari subsistem yang terhubung sebagaimana informasi di atas maka dapatlah dibentuk sebuah model subsistem dengan model interaksi sebagai berikut:

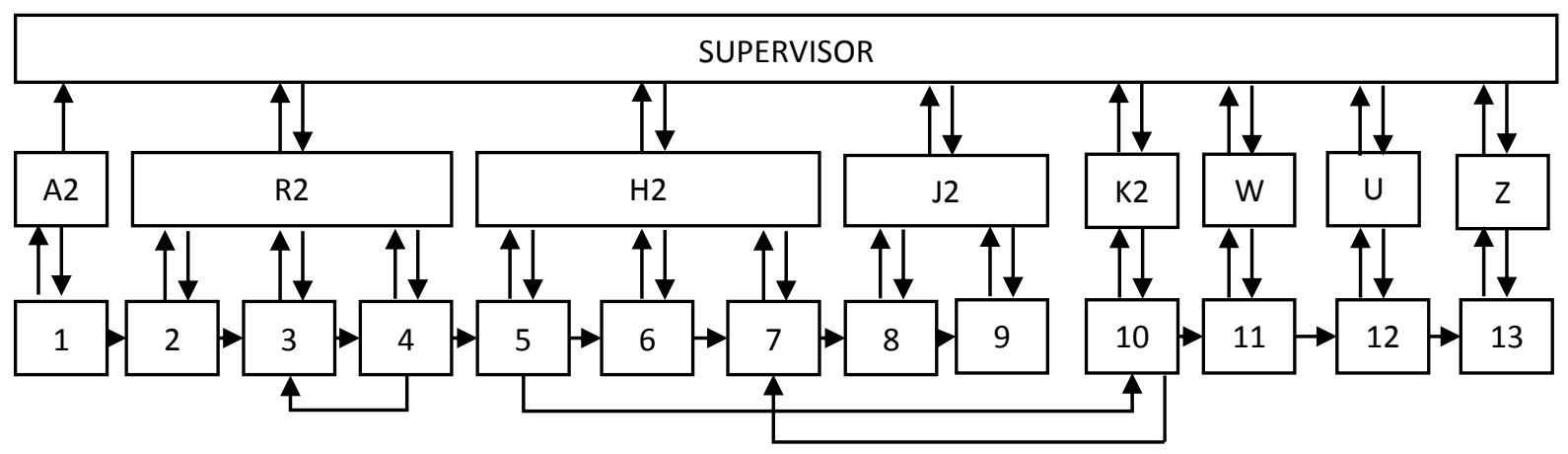

Gambar 6 Aliras Proses pada Power Plant PLTU 
a. Subsistem I

$$
\begin{aligned}
& \dot{x}_{1}=A_{1} x_{1}+B_{1} u_{1} \\
& y_{1}=C_{1} x_{1}+D_{1} u_{1} \\
& z_{1}=C_{z 1} x_{1}+D_{z 1} u_{1} \\
& L=0
\end{aligned}
$$

b. Subsistem II

$$
\begin{aligned}
& \dot{x}_{2}=A_{2} x_{2}+B_{2} u_{2}+E_{2} s_{2} \\
& y_{2}=C_{2} x_{2}+D_{2} u_{2}+F_{2} s_{2} \\
& z_{2}=C_{z 2} x_{2}+D_{z 2} u_{2}+F_{2} s_{2} \\
& L=L_{21} z_{1}
\end{aligned}
$$

c. Subsistem III

$$
\begin{aligned}
& \dot{x}_{3}=A_{3} x_{3}+B_{3} u_{3}+E_{3} s_{3} \\
& y_{3}=C_{3} x_{3}+D_{3} u_{3}+F_{3} s_{3} \\
& z_{3}=C_{z 3} x_{3}+D_{z 3} u_{3}+F_{3} s_{3} \\
& L=L_{32} z_{2}+L_{35} z_{5}
\end{aligned}
$$

d. Subsistem IV

$$
\begin{aligned}
& \dot{x}_{4}=A_{4} x_{4}+B_{4} u_{4}+E_{4} s_{4} \\
& y_{4}=C_{4} x_{4}+D_{4} u_{4}+F_{4} s_{4} \\
& z_{4}=C_{z 4} x_{4}+D_{z 4} u_{4}+F_{4} s_{4} \\
& L=L_{43} z_{3}
\end{aligned}
$$

e. Subsistem V

$$
\begin{aligned}
& \dot{x}_{5}=A_{5} x_{5}+B_{5} u_{5}+E_{5} s_{5} \\
& y_{5}=C_{5} x_{5}+D_{5} u_{5}+F_{5} s_{5} \\
& z_{5}=C_{z 5} x_{5}+D_{z 5} u_{5}+F_{5} s_{5} \\
& L=L_{54} z_{4}
\end{aligned}
$$

f. Subsistem VI

$$
\begin{aligned}
& \dot{x}_{6}=A_{6} x_{6}+B_{6} u_{6}+E_{6} s_{6} \\
& y_{6}=C_{6} x_{6}+D_{6} u_{6}+F_{6} s_{6} \\
& z_{6}=C_{z 6} x_{6}+D_{z 6} u_{6}+F_{6} s_{6} \\
& L=L_{65} z_{5}
\end{aligned}
$$

g. Subsistem VII

$$
\begin{aligned}
& \dot{x}_{7}=A_{7} x_{7}+B_{7} u_{7}+E_{7} s_{7} \\
& y_{7}=C_{7} x_{7}+D_{7} u_{7}+F_{7} s_{7} \\
& z_{7}=C_{z 7} x_{7}+D_{z 7} u_{7}+F_{7} s_{7} \\
& L=L_{76} z_{6}
\end{aligned}
$$

h. Subsistem VIII

$$
\begin{aligned}
& \dot{x}_{8}=A_{8} x_{8}+B_{8} u_{8}+E_{8} s_{8} \\
& y_{8}=C_{8} x_{8}+D_{8} u_{8}+F_{8} s_{8} \\
& z_{8}=C_{z 8} x_{8}+D_{z 8} u_{8}+F_{8} s_{8} \\
& L=L_{87} z_{7}
\end{aligned}
$$

Dari persamaan subsistem-subsistem diatas dibentuk matrik interaksi $(L)$ berikut ini:

$$
L=\left[\begin{array}{llllllll}
0 & 0 & 0 & 0 & 0 & 0 & 0 & 0 \\
I & 0 & 0 & 0 & 0 & 0 & 0 & 0 \\
0 & I & 0 & 0 & I & 0 & 0 & 0 \\
0 & 0 & I & 0 & 0 & 0 & 0 & 0 \\
0 & 0 & 0 & I & 0 & 0 & 0 & 0 \\
0 & 0 & 0 & 0 & I & 0 & 0 & 0 \\
0 & 0 & 0 & 0 & 0 & I & 0 & 0 \\
0 & 0 & 0 & 0 & 0 & 0 & I & 0
\end{array}\right]
$$

Sistem pada power plant PLTU diatas merupakan pengolahan proses yang tidak memiliki troughput (pada sistem ini kondisi input menjadi output) sehingga berlaku pada persamaan (5) dan (6) jadi persamaan struktur sistem dalam model input output menjadi:

$$
\begin{aligned}
& \dot{x}=\left[\begin{array}{cccccccc}
A_{1} & 0 & 0 & 0 & 0 & 0 & 0 & 0 \\
E_{2} C_{z 1} & A_{2} & 0 & 0 & 0 & 0 & 0 & 0 \\
0 & E_{3} C_{z 2} & A_{3} & 0 & E_{3} C_{z 5} & 0 & 0 & 0 \\
0 & 0 & E_{4} C_{z 3} & A_{4} & 0 & 0 & 0 & 0 \\
0 & 0 & 0 & E_{5} C_{z 4} & A_{5} & 0 & 0 & 0 \\
0 & 0 & 0 & 0 & E_{6} C_{z 5} & A_{6} & 0 & 0 \\
0 & 0 & 0 & 0 & 0 & E_{7} C_{z 6} & A_{7} & 0 \\
0 & 0 & 0 & 0 & 0 & 0 & E_{8} C_{z 7} & A_{8}
\end{array}\right] x \\
& +\left[\begin{array}{ccccccccccc}
B_{1} & 0 & 0 & 0 & 0 & 0 & 0 & 0 \\
0 & B_{2} & 0 & 0 & 0 & 0 & 0 & 0 \\
0 & 0 & B_{3} & 0 & 0 & 0 & 0 & 0 \\
0 & 0 & 0 & B_{4} & 0 & 0 & 0 & 0 \\
0 & 0 & 0 & 0 & B_{5} & 0 & 0 & 0 \\
0 & 0 & 0 & 0 & 0 & B_{6} & 0 & 0 \\
0 & 0 & 0 & 0 & 0 & 0 & B_{7} & 0 \\
0 & 0 & 0 & 0 & 0 & 0 & 0 & B_{8}
\end{array}\right] u \\
& y
\end{aligned}
$$

\section{Analisis dan Pembahasan}

Dari persamaan diatas maka kita dapat menyusun suatu matrik struktur sebagai berikut:

$$
S_{a}=\left[\begin{array}{llllllll}
1 & 0 & 0 & 0 & 0 & 0 & 0 & 0 \\
1 & 1 & 0 & 0 & 0 & 0 & 0 & 0 \\
0 & 1 & 1 & 0 & 1 & 0 & 0 & 0 \\
0 & 0 & 1 & 1 & 0 & 0 & 0 & 0 \\
0 & 0 & 0 & 1 & 1 & 0 & 0 & 0 \\
0 & 0 & 0 & 0 & 1 & 1 & 0 & 0 \\
0 & 0 & 0 & 0 & 0 & 1 & 1 & 0 \\
0 & 0 & 0 & 0 & 0 & 0 & 1 & 1
\end{array}\right]
$$




$$
\begin{aligned}
S_{b} & =\left[\begin{array}{llllllll}
1 & 0 & 0 & 0 & 0 & 0 & 0 & 0 \\
0 & 1 & 0 & 0 & 0 & 0 & 0 & 0 \\
0 & 0 & 1 & 0 & 0 & 0 & 0 & 0 \\
0 & 0 & 0 & 1 & 0 & 0 & 0 & 0 \\
0 & 0 & 0 & 0 & 1 & 0 & 0 & 0 \\
0 & 0 & 0 & 0 & 0 & 1 & 0 & 0 \\
0 & 0 & 0 & 0 & 0 & 0 & 1 & 0 \\
0 & 0 & 0 & 0 & 0 & 0 & 0 & 1
\end{array}\right] \\
S_{c} & =\left[\begin{array}{llllllll}
1 & 0 & 0 & 0 & 0 & 0 & 0 & 0 \\
0 & 1 & 0 & 0 & 0 & 0 & 0 & 0 \\
0 & 0 & 1 & 0 & 0 & 0 & 0 & 0 \\
0 & 0 & 0 & 1 & 0 & 0 & 0 & 0 \\
0 & 0 & 0 & 0 & 1 & 0 & 0 & 0 \\
0 & 0 & 0 & 0 & 0 & 1 & 0 & 0 \\
0 & 0 & 0 & 0 & 0 & 0 & 1 & 0 \\
0 & 0 & 0 & 0 & 0 & 0 & 0 & 1
\end{array}\right]
\end{aligned}
$$

Diatas merupakan kondisi dari struktur-rank (SRank) untuk $\left[\begin{array}{ll}S_{a} & S_{b}\end{array}\right]$ dan $\left[\begin{array}{ll}S_{a} & S_{c}\end{array}\right]^{\mathrm{T}}$ dari sistem diatas. Adapun struktur-rank (S-Rank) dari $\left[\begin{array}{ll}S_{a} & S_{b}\end{array}\right]=8$ dengan S-Rank $\left[\begin{array}{ll}S_{a} & S_{c}\end{array}\right]^{\mathrm{T}}=8$. Hal ini menunjukan bahwa sistem tersebut bisa dikatakan controllable dan observable karena syarat dari sistem tersebut output dan input reachable (yaitu ada lintasan yang menghubunkan salah satu input ke setiap state). Selanjutnya kita dekomposisi kan menjadi subsistem-subsistem yang dapat disusun secara struktur hirarki.

$$
L=\left[\begin{array}{c:cccc:c:cc}
0 & 0 & 0 & 0 & 0 & 0 & 0 & 0 \\
\hdashline L_{22} & 0 & 0 & 0 & 0 & 0 & 0 & 0 \\
0 & L_{32} & 0 & 0 & L_{35} & 0 & 0 & 0 \\
0 & 0 & L_{43} & 0 & 0 & 0 & 0 & 0 \\
0 & 0 & 0 & L_{54} & 0 & 0 & 0 & 0 \\
\hdashline 0 & 0 & 0 & 0 & L_{6} & 0 & 0 & 0 \\
\hdashline 0 & 0 & 0 & 0 & 0 & L_{76} & 0 & 0 \\
\hdashline 0 & 0 & 0 & 0 & 0 & 0 & L_{87} & 0
\end{array}\right]
$$

Dari struktur matrik L terbukti bahwa matrik tersebut merupakan lower diagonal bahwa pengendalian proses diatas mempunyai struktur berhirarki. Matriks diatas diddekomposisi menjadi 6 subsistem baru yang mempunyai karakteristik strongly coupled sistem. Persamaan sistem tiap strongly coupled sistem adalah sebagai berikut:

1. SCS 1 (Level 6)

$$
\begin{aligned}
& \dot{x}_{1}=A_{1} x_{1}+B_{1} u_{1} \\
& y_{1}=C_{1} x_{1}
\end{aligned}
$$

2. SCS 2 (Level 5)

$$
\begin{aligned}
& \dot{x}_{2}=A_{2} x_{2}+B_{2} u_{2} \\
& y_{2}=C_{2} x_{2}
\end{aligned}
$$

3. SCS 3 (Level 4)

$$
\begin{aligned}
& {\left[\begin{array}{l}
\dot{x}_{3} \\
\dot{x}_{4} \\
\dot{x}_{5}
\end{array}\right]=} {\left[\begin{array}{ccc}
A_{3} & 0 & E_{3} C_{z 5} \\
E_{4} C_{z 3} & A_{4} & 0 \\
0 & E_{5} C_{z 4} & A_{5}
\end{array}\right]\left[\begin{array}{l}
x_{3} \\
x_{4} \\
x_{5}
\end{array}\right]+} \\
& {\left[\begin{array}{ccc}
B_{3} & 0 & 0 \\
0 & B_{4} & 0 \\
0 & 0 & B_{5}
\end{array}\right]\left[\begin{array}{l}
u_{3} \\
u_{4} \\
u_{5}
\end{array}\right] } \\
& {\left[\begin{array}{l}
y_{3} \\
y_{4} \\
y_{5}
\end{array}\right]=\left[\begin{array}{ccc}
C_{3} & 0 & 0 \\
0 & C_{4} & 0 \\
0 & 0 & C_{5}
\end{array}\right]\left[\begin{array}{l}
x_{3} \\
x_{4} \\
x_{5}
\end{array}\right] }
\end{aligned}
$$

4. SCS 4 (Level 3)

$$
\begin{aligned}
& \dot{x}_{6}=A_{6} x_{6}+B_{6} u_{6} \\
& y_{6}=C_{6} x_{6}
\end{aligned}
$$

5. SCS 5 (Level 2)

$$
\begin{aligned}
& \dot{x}_{7}=A_{7} x_{7}+B_{7} u_{7} \\
& y_{7}=C_{7} x_{7}
\end{aligned}
$$

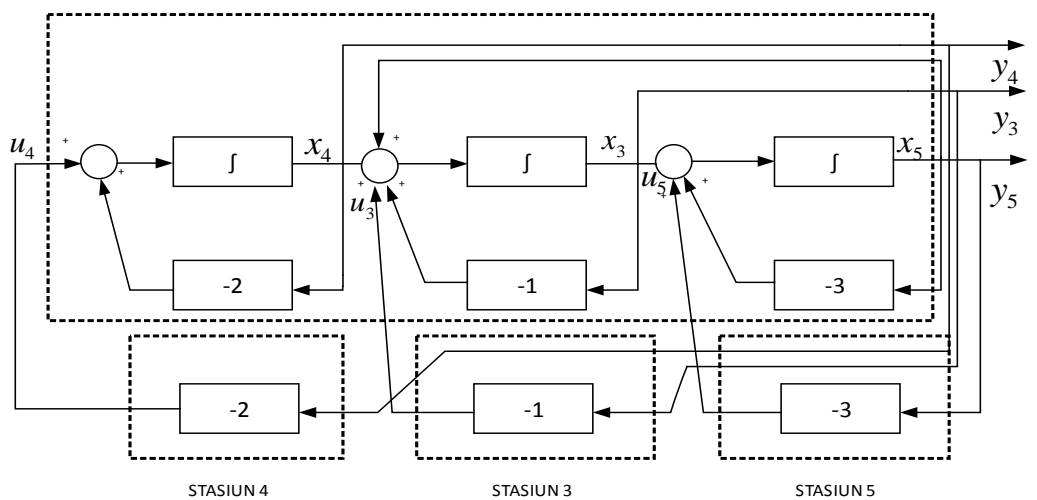

Gambar 7 Diagram Blok SCS3 dengan Kompensator Terdesentralisasi statis 
6. SCS 6 (Level 1)

$$
\begin{aligned}
& \dot{x}_{8}=A_{8} x_{8}+B_{8} u_{8} \\
& y_{8}=C_{8} x_{8}
\end{aligned}
$$

Pengelomokkan tersebut tentunya berdasar pada graph struktur sistem dengan memperhatikan interaksi pada L. Dekomposisi sistem dapat mempermudah analisa kestabilan sistem, karena suatu sistem dikatakan stabil jika dan hanya jika semua strongly coupled sistem adalah stabil. Karena sistem pengendalian pada power plant di atas mempunyai matriks interaksi $L$ yang lower diagonal maka sistem tersebut mempunyai struktur berhirarki.

Sistem dikatakan stabil jika dan hanya jika semua eigenvalue sistem tersebut berada pada bagian negative bidang kompleks. Setelah didekomposisi sistem dikatakan stabil dan hanya jika semua SCS nya stabil.

Kita asumsikan tiap susbsistem adalah orde 1 dengan konstan waktu (T) untuk tiap subsistem adalah $1,0.5,1,1,1,0.5,0.2,1$ maka persamaan sustem untuk tiap SCS adalah:

1. SCS 1 (Level 6)

$$
\begin{aligned}
& \dot{x}_{1}=-x_{1}+u_{1} \\
& y_{1}=x_{1}
\end{aligned}
$$

2. SCS 2 (Level 5)

$$
\begin{aligned}
& \dot{x}_{2}=-2 x_{2}+2 u_{2} \\
& y_{2}=x_{2}
\end{aligned}
$$

3. SCS 3 (Level 4)

$$
\begin{aligned}
& {\left[\begin{array}{l}
\dot{x}_{3} \\
\dot{x}_{4} \\
\dot{x}_{5}
\end{array}\right]=\left[\begin{array}{ccc}
-1 & 0 & 1 \\
1 & -1 & 0 \\
0 & 1 & -1
\end{array}\right]\left[\begin{array}{l}
x_{3} \\
x_{4} \\
x_{5}
\end{array}\right]+} \\
& {\left[\begin{array}{lll}
1 & 0 & 0 \\
0 & 1 & 0 \\
0 & 0 & 1
\end{array}\right]\left[\begin{array}{l}
u_{3} \\
u_{4} \\
u_{5}
\end{array}\right]} \\
& {\left[\begin{array}{l}
y_{3} \\
y_{4} \\
y_{5}
\end{array}\right]=\left[\begin{array}{lll}
1 & 0 & 0 \\
0 & 1 & 0 \\
0 & 0 & 1
\end{array}\right]\left[\begin{array}{l}
x_{3} \\
x_{4} \\
x_{5}
\end{array}\right]}
\end{aligned}
$$

4. SCS 4 (Level 3)

$$
\begin{aligned}
& \dot{x}_{6}=-2 x_{6}+2 u_{6} \\
& y_{6}=x_{6}
\end{aligned}
$$

5. SCS 5 (Level 2)

$$
\begin{aligned}
& \dot{x}_{7}=-5 x_{7}+5 u_{7} \\
& y_{7}=x_{7}
\end{aligned}
$$

6. SCS 6 (Level 1)

$$
\begin{aligned}
& \dot{x}_{8}=-x_{8}+u_{8} \\
& y_{8}=x_{8}
\end{aligned}
$$

Untuk menentukan kestabilan sistem diatas maka akan dicari eigenvalue masing-masing strongly coupled sistem diatas

SCS 1, mempunyai eigenvalue pada $\lambda_{1}=-1$

scs 2, mempunyai eigenvalue pada $\lambda_{2}=-2$ scs 3, mempunyai eigenvalue pada $\lambda_{3}=-1.5+0.866 i, \quad \lambda_{4}=-1.5+0.866 i, \quad \lambda_{5}=0$

scs 4 , mempunyai eigenvalue pada $\lambda_{6}=-2$

ScS 5, mempunyai eigenvalue pada $\lambda_{7}=-5$

ScS 6, mempunyai eigenvalue pada $\lambda_{8}=-1$

Terdapat satu eigenvalue yaitu $\lambda_{5}=0$ sehingga SCS3 diperkirakan tidak stabil akan mengakibatkan sistem lebih labil. Sistem yang tidak stabil dapat distabilkan dengan menggunakan pengendalian terdesentralisasi dengan syarat sistem tersebut tidak memiliki fixed mode terdesentralisasi. Sistem dapat distabilkan dengan memberikan kompensator terdesentralisasi statis pada sistem. Kompensator berupa umpan balik dari $y_{3}$ ke $u_{3}, y_{4}$ ke $u_{4}$ dan $y_{5}$ ke $u_{5}$.

$$
\begin{aligned}
& u_{3}=-K_{3} y_{3} \\
& u_{4}=-K_{4} y_{4} \\
& u_{5}=-K_{5} y
\end{aligned}
$$

Sehingga,

$$
\begin{aligned}
A-B K C & =\left[\begin{array}{ccc}
-1 & 0 & 1 \\
1 & -1 & 0 \\
0 & 1 & -1
\end{array}\right]-\left[\begin{array}{ccc}
1 & 0 & 0 \\
0 & 1 & 0 \\
0 & 0 & 1
\end{array}\right]\left[\begin{array}{ccc}
K_{3} & 0 & 0 \\
0 & K_{4} & 0 \\
0 & 0 & K_{5}
\end{array}\right] \\
& =\left[\begin{array}{ccc}
-1 & 0 & 1 \\
1 & -1 & 0 \\
0 & 1 & -1
\end{array}\right]-\left[\begin{array}{ccc}
K_{3} & 0 & 0 \\
0 & K_{4} & 0 \\
0 & 0 & K_{5}
\end{array}\right] \\
& =\left[\begin{array}{ccc}
-1-K_{3} & 0 & 1 \\
1 & -1-K_{4} & 0 \\
0 & 1 & -1-K_{5}
\end{array}\right]
\end{aligned}
$$

Eigenvalue dicari dari persamaan $|\lambda I-(A-B K C)|=0$, sehingga diperoleh

$$
\begin{aligned}
& {\left[\begin{array}{ccc}
\lambda-\left(-1-K_{3}\right) & 0 & 1 \\
1 & \lambda-\left(-1-K_{4}\right) & 0 \\
0 & 1 & \lambda-\left(-1-K_{5}\right)
\end{array}\right]=0} \\
& \lambda^{3}+\left(2+K_{3} K_{5}+K_{4} K_{5}\right) \lambda^{2}+\left(K_{4} K_{5}+K_{3} K_{5}+K_{3} K_{4} K_{5}\right)+1=0
\end{aligned}
$$


Jika diasumsukan spectrum loop tertutup $\sigma_{0}=$ $-2,-3,-4$ maka akan mendapatkan persamaan

$$
\left(-1+K_{3}\right)\left(-2+K_{4}\right)\left(-3+K_{5}\right)=0
$$

Maka dieperoleh kompensator statis $K_{3}=1, K_{4}=$ 2 dan $K_{5}=3$, sehingga aksi kendalinya adalah

$u_{3}=-1 y_{3}, u_{4}=-2 y_{3}$ dan $u_{5}=-3 y_{3}$.

Gambar 7 diatas merupakan diagram blok SCS3 ditambah kompensator $K_{3}, K_{4}$ dan $K_{5}$ kemudian dipasang pada stasiun kendali 3, 4 dan 5 menjadi sistem yang stabil.

\section{Kesimpulan}

Dari hasil analisis diatas sistem mempunyai input langsung menjadi output (troughput) dan sistem diatas memenuhi syarat input dan outputnya reachable sehingga sistem bisa dikatakan controllable dan observable. Untuk menghasilkan sistem stabil di ketahui bahwa persamaan karakteristiknya berada di sebelah kiri bidang S, terdapat SCS3 yang tidak stabil karna salah satu $\lambda_{5}=0$ maka distabilkan menggunakan pengendalian terdesentralisasi dengan memberikan kompensator.

\section{Daftar Pustaka.}

[1] Khairudin, Moh. "sistem kendali pada sistem kompleks multivariable dengan metode berhirarki" (Telecommunication Computing Electronics and Control) 3.1 (2005): 27-37.

[2] Koo, Geun Bum, Jin Bae Park, and Young Hoon Joo. "Decentralized fuzzy observer-based output-feedback control for nonlinear largescale sistems: an LMI approach." Fuzzy Sistems, IEEE Transactions on 22.2 (2014): 406-419.

[3] Albertoe, P \& Sala, A "Multivariable Control System: An Engineering Approach" Springer: Verlag London, London 2004.

[4] Lunze, Jan, "Feedback Control of Large Scale System" PrenticeHall International, Englewood Cliffs, 1992.

[5] Li, Duan. "Hierarchical control for large-scale systems with general multiple linear-quadratic structure." Automatica 29.6 (1993): 14511461.

[6] Ngan, H. W., A. K. David, and K. L. Lo. "Decentralized hierarchical optimal control of dynamic instability in AC/DC power systems." International Journal of Electrical Power \&Energy Systems 14.5 (1992): 358363. 